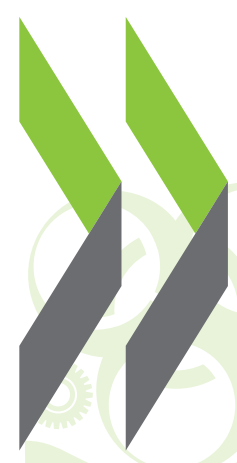

\title{
Students' numeracy skills and practices
}

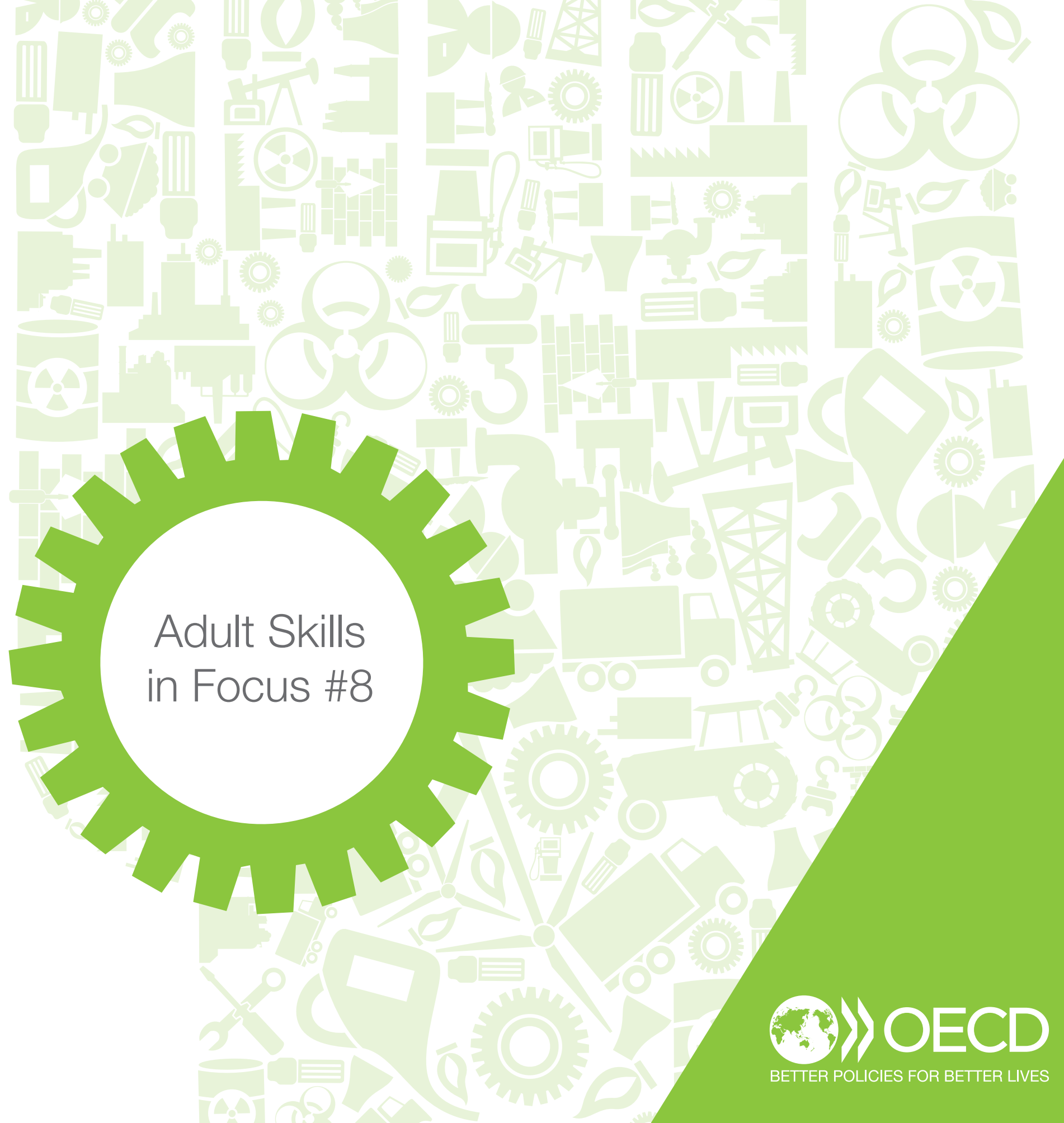




\section{ADULT SKILLS \\ IN FOCUS}

- Students have a higher average level of numeracy proficiency than adults who are not in education, and are more likely to be intensively engaged in numeracy practices by using their skills daily.

- Students are most likely to be intensively engaged in numeracy practices in the Czech Republic and Finland, and least likely in Turkey and England/Northern Ireland (United Kingdom). The percentage of students making little use of numeracy is highest in Turkey and Japan and lowest in Finland and the Czech Republic.

- Field of study and numeracy level are the two clearest positive predictors of how intensely students engage in numeracy practices.

The numeracy performance of the adult population of the countries participating in the OECD's Programme for the International Assessment of Adult Competencies (PIAAC) reveals a clear difference in favour of the younger generations. While there may be several factors behind this overall improvement, the most important are changes in education systems leading to wider and more inclusive participation in higher education. Given the importance of numeracy if individuals are to actively participate in fast-changing economies, it is important to identify factors that may further improve students' familiarity with numeracy practices.

\section{Students have a significantly higher average numeracy score than adults who are not in education}

PIAAC assesses the information-processing skills of adults aged 16 to 65 in the 33 countries/ economies that participated in the survey. Overall, the average numeracy score is 263 points, ranging from 206.1 points in Chile to 288.2 points in Japan.
If we distinguish students from other adults, we find that their numeracy performance is much higher, although still very variable, ranging from 239.6 points in Chile to 296.6 points in Finland, and averaging 276.5 points.

Figure 1 / Difference in average numeracy score between students and non-students

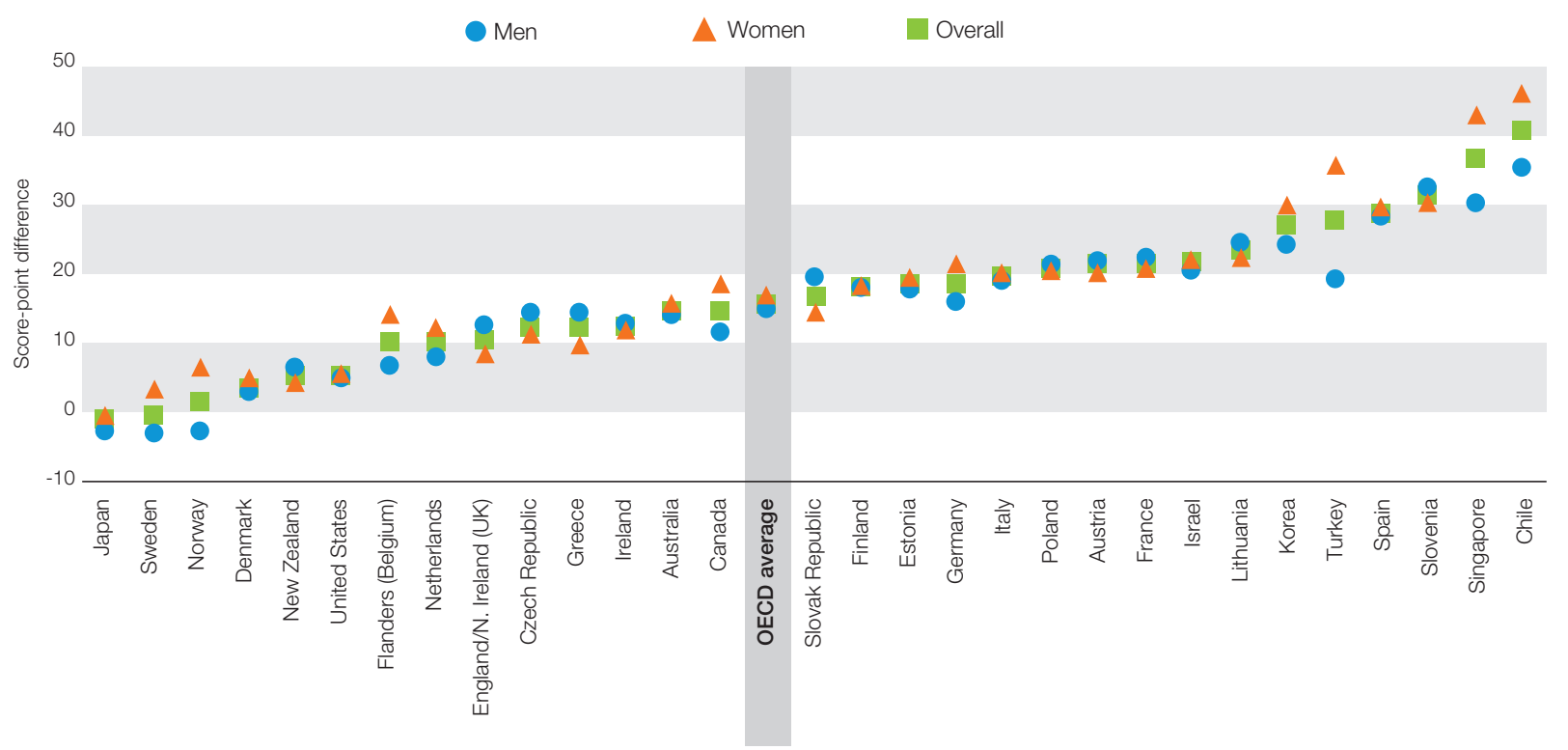


The difference in performance between students and non-students varies but is always positive (Figure 1). With the exception of Japan, Sweden and Norway, where it is not significantly different from zero, the gap between the two groups ranges from 3.5 points in Denmark to 40.7 points in Chile. Of the seven countries or economies where the gap is less than or equal to 10 points, six have a population whose average numeracy performance is well above the OECD average - Denmark, Flanders (Belgium), Japan, New Zealand, Norway and Sweden - and only one where it is well below (the United States). The difference is more than 30 points in three countries: Slovenia (31.2 points), Singapore (36.7 points) and Chile (40.7 points).

The size of the gap in each country is roughly similar for men and women, although it tends to be larger among women. This is particularly the case in three countries, Turkey, Singapore and Chile, where the gap observed between female students and non-students is 16.3, 12.6 and 10.7 points greater respectively than that observed in the male population. These cases reflect a catch-up phenomenon: young women are participating in education in greater numbers and for longer than older women did, as a result of which the average numeracy score of the female population is drawing closer to that of the male population.

Given that students' more-or-less regular engagement in numeracy practices is one mechanism by which they develop their skills over the long term, it is legitimate to ask whether the variations in scores observed between countries can be explained by the differences in the intensity of engagement in numeracy in everyday practices.

\section{The intensity of students' engagement in numeracy practices is very high, but also varies greatly from country to country}

To analyse the intensity of engagement in numeracy practices, responses to eight items concerning the practice of numeracy-related activities in the PIAAC questionnaire have been modelled by a variable with values between 0 (for those who never engage in any of the eight activities) and 1 (for those who engage in all the practices every day). Adults were then divided into three groups based on these scores, characterising the level of their engagement: limited (the bottom $40 \%$ of adults), median (35\% of adults) or intensive (25\% of adults).

Students aged 16 and over show more frequent and sustained engagement than other adults in numeracy-related activities in their everyday lives, i.e. in both their daily lives and their studies.

Figure 2 / Distribution of students by classification for engagement of intensity in numeracy practices, by country

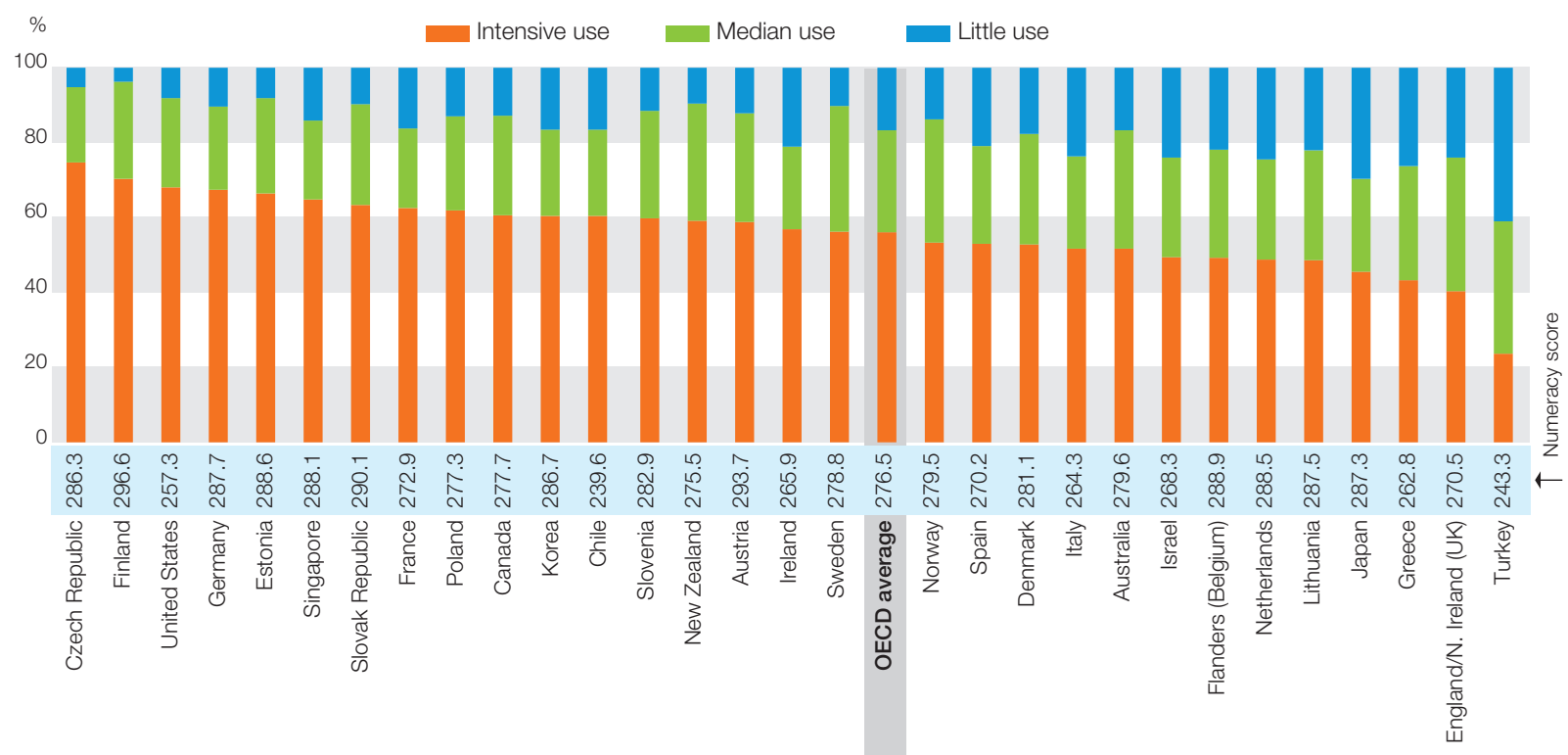

Source: Survey of Adult Skills (PIAAC) (2012, 2015), www.oecd.org/skills/piaac/publicdataandanalysis. 


\section{ADULT SKILLS}

INFOCUS

For the population as a whole, one in four adults make intensive use of numeracy practices in their everyday lives, whereas for students the proportion is more than one in two in the majority of countries that participated in the survey. In only one country is the percentage of students at this level of engagement below 25\% (Turkey) and in only seven is it below 50\%: England/Northern Ireland (United Kingdom), Greece, Japan, Lithuania, the Netherlands, Flanders (Belgium) and Israel (Figure 2). At the other end of the spectrum, at least two-thirds of students in the Czech Republic, Finland, the United States and Germany make intensive use of numeracy.

The fact that countries/economies rank differently according to their students' numeracy performance and their engagement in numeracy practices suggests that mastery of skills and their use are two partly separate concepts. Factors relating to education (such as field of study) may lead to students using these skills more or less frequently in their daily lives.

\section{Proficiency in numeracy, unlike proficiency in literacy, is an important predictor of engagement in numeracy practices}

All other things being equal, proficiency in numeracy is the factor most closely linked with engagement in numeracy practices (0.265) among students, except in Turkey. Literacy proficiency, which was also assessed in the PIAAC survey, plays a negligible role when the results are controlled for students' individual characteristics and the specific characteristics of their studies (Figure 3).

Field of study related to mathematics and sciences displays a positive but relatively weak link with the intensity of numeracy practices (0.079), whereas educational attainment (estimated by the number of years of education corresponding to the highest qualification obtained) has a negative effect (-0.091). This means that, all other things being equal, one additional year of education decreases the intensity of engagement in numeracy practice by an average of 0.09 on a scale from 0 to 1 . Given that highly specialised mathematics and science courses are associated with higher education rather than secondary education, which tends to be more general in nature, these results may seem contradictory. But while the level of numeracy required in courses with a significant

\section{Figure 3 / Graphical representation of factors in students' intensity of engagement in numeracy practices}

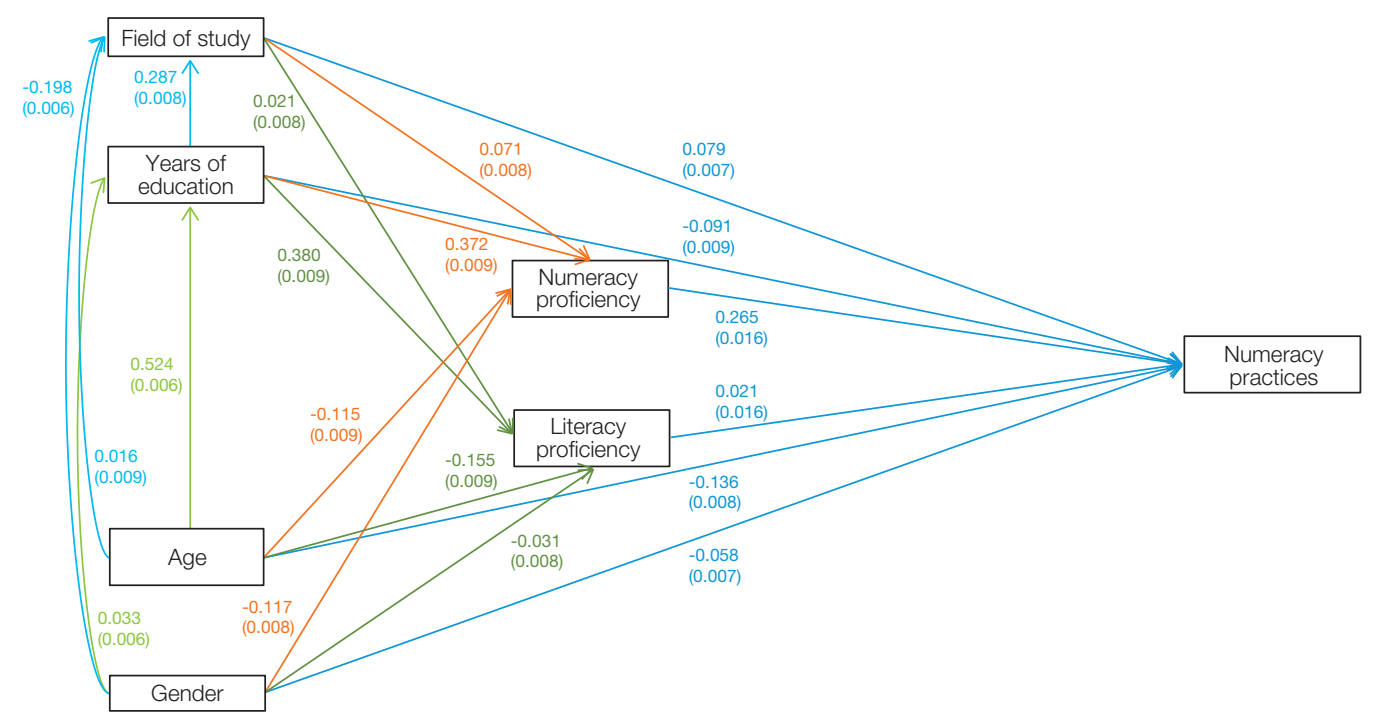

Note: The coefficients displayed represent the average of the countries' coefficients and the numbers in brackets represent the standard errors for each coefficient. Source: Survey of Adult Skills (PIAAC) $(2012,2015)$, www.oecd.org/skills/piaac/publicdataandanalysis. 
mathematical content increases with the level of education, the proportion of students participating in such courses decreases considerably as students progress from secondary to tertiary education. As a result, the average intensity of numeracy practice is lower among students with a longer educational career (reaching tertiary level) than among those who have only attained or are still engaged in a lower level of education.

Age also has a strong negative impact (-0.136).
This coefficient is explained by the correlation between age and the time taken to complete studies. At any given level of education, a one-year increase in a student's age reflects a delay of one year in the normal completion of a study cycle compared to the reference group. It is therefore understandable that, all other things being equal, older students perform less well in literacy and numeracy and engage less in the common uses of numeracy.

\section{In some countries, the relationship between students' engagement in numeracy practices and their level of proficiency is much stronger}

The intensity of engagement in numeracy practices is always positively associated with numeracy proficiency, but the degree varies widely between countries. For example, an increase of one level in numeracy proficiency is related to an increase of 0.42 points in the index for intensity of engagement in Japan, compared to just 0.14 points in Greece and Slovenia. The greater the magnitude of the effect, the more it reflects pronounced differences in students' habits as regards the practice of numeracy, which may contribute to the emergence of inequalities. Students with the least proficiency in numeracy engage far less intensively in it than their more proficient peers, which may in turn restrict their ability to acquire new skills or use the skills they already possess correctly.

Being a woman also often has a negative effect on the intensity of engagement in numeracy. This means that gender inequalities tend to increase during the period of study: not only are female students slightly less proficient in numeracy than male students, but those at an equal proficiency level tend to engage slightly less intensively in numeracy practices in their everyday lives. This trend is particularly pronounced in Germany, Norway, Italy, the Netherlands and Turkey.

Figure 4 / Impact of proficiency in literacy and numeracy, field of study and gender on intensity of engagement in numeracy practices

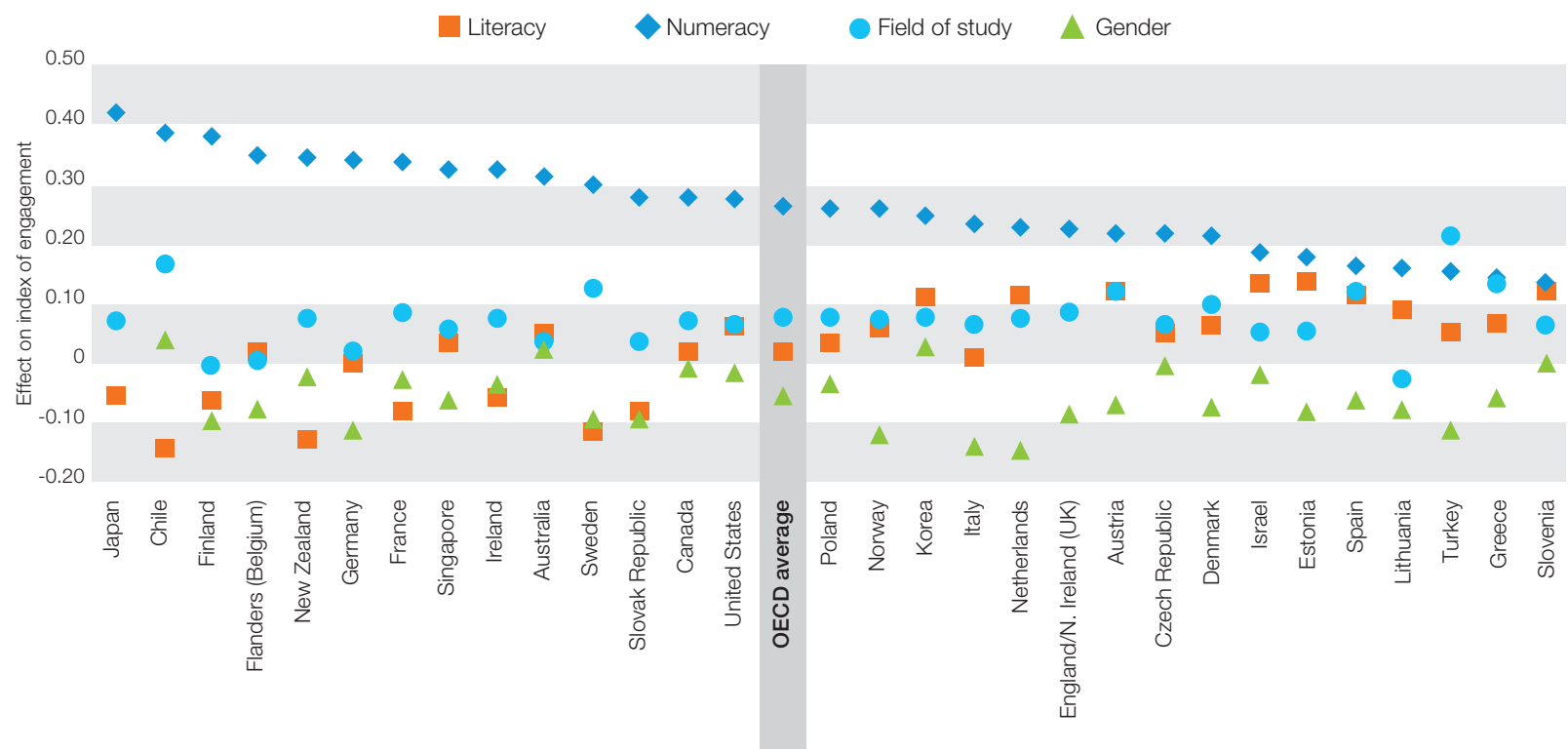

Note: Results controlled for age and number of years of schooling.

Source: Survey of Adult Skills (PIAAC) $(2012,2015)$, www.oecd.org/skills/piaac/publicdataandanalysis. 


\section{The bottom line \\ The results of the Survey of Adult Skills confirm that there is a strong link between the level of numeracy performance and the use of these skills in practice. In view of these findings, countries could further encourage the teaching of numeracy-related disciplines in a wider variety of higher education pathways. Such a measure is particularly important as numeracy skills and practices play a crucial role in many dimensions of individual well-being.}

\section{$>$ CONTACT: \\ $>$ FOR MORE \\ INFORMATION:}

$>$ VISIT:
Nicolas Jonas (icolas.Jonas@oecd.org), edu.piaac@oecd.org

Jonas N. (2018), "Numeracy Practices and Numeracy Skills among Adults", OECD Education Working Papers, No. 177, OECD Publishing, Paris https://doi.org/10.1787/8f19fc9f-en.

www.oecd.org/skills/piaac/

Education Indicators in Focus - PISA in Focus - Teaching in Focus.

\section{The Survey of Adult Skills is a product of the OECD Programme for the International Assessment of Adult Competencies (PIAAC).}

This paper is published under the responsibility of the Secretary-General of the OECD. The opinions expressed and the arguments employed herein do not necessarily reflect the official views of OECD member countries.

This document and any map included herein are without prejudice to the status of or sovereignty over any territory, to the delimitation of international frontiers and boundaries and to the name of any territory, city or area.

You can copy, download or print OECD content for your own use, and you can include excerpts from OECD publications, databases and multimedia products in your own documents, presentations, blogs, websites and teaching materials, provided that suitable acknowledgment of OECD as source and copyright owner is given. All requests for commercial use and translation rights should be submitted to rights@oecd.org.

The statistical data for Israel are supplied by and under the responsibility of the relevant Israeli authorities. The use of such data by the OECD is without prejudice to the status of the Golan Heights, East Jerusalem and Israeli settlements in the West Bank under the terms of international law. 